\title{
Which one is the best? A quasi-experimental study comparing frameworks for unplugged gamification
}

\author{
Wilk Oliveira ${ }^{1}$, Armando M. Toda ${ }^{1}$, Paula T. Palomino ${ }^{1}$, Luiz Rodrigues ${ }^{1}$ \\ Seiji Isotani ${ }^{1}$ \\ ${ }^{1}$ Institute of Mathematical and Computer Sciences - University of São Paulo (USP) \\ \{wilk.oliveira, armando.toda, paulatpalomino, lalrodrigues\}@usp.br, \\ sisotanilicmc.usp.br
}

\begin{abstract}
Despite many studies proposing and evaluating frameworks to design gamified environments in education, there is still difficulty in making end-users (e.g., teachers, instructors, and designers) use these services and assess which ones are most appropriate for their context. We tackled this challenge by comparing two frameworks to design a gamified non-virtual class, through a quasiexperimental study. Our main results indicate that one of the frameworks (Six Steps to Gamification - 6D) proved to be more adaptable to the context and the other (GAMIFY-SN) was more complete to associate the gamification elements within the instructor's final objectives in the gamified class. Thus, our results promote a contribution to end-users through insights on which the most suitable framework to use in each situation.
\end{abstract}

\section{Introduction}

In the last ten years, many studies have sought to use gamification $\rrbracket^{1}$ as a strategy to improve learning outcomes [Oliveira and Bittencourt 2019], for example, to increase students' motivation [Monterrat et al. 2014], engagement [Hamari et al. 2016] and flow experience [Oliveira et al. 2020] in the non-virtual classrooms or online educational systems [Santos et al. 2018]. However, the results in applying gamification in this context, specially in unplugged environments? still present contradictory results [Toda et al. 2017], leading studies to the need to improve different aspects of gamification [Rapp et al. 2019].

One of the lines of thought regarding the contradictory results in the application of gamification is that it is necessary to provide strategies. Recent literature on the subject states that gamification needs a well-thought design to achieve the desired positive effects (e.g., frameworks ${ }^{3}$ and methodologies) [Gomes et al. 2019, Rauschenberger et al. 2019, Pastushenko et al. 2020]. Even though some studies have proposed and evaluated frameworks in education domain [Werbach and Hunter 2012, Toda et al. 2019a, Morschheuser et al. 2017], there is still some field to explore such as a) few studies apply these frameworks in a real context (e.g., classroom or development of gamified systems) [Toda et al. 2018b] and $b$ ) no studies compare existing frameworks, which difficulties the decision making process by the end-users to choose one framework suitable for their contexts. This means that although there are several frameworks, it is very difficult for end-users to know which framework to choose to apply in their context.

\footnotetext{
1"Use of games elements in non-game contexts" [Deterding et al. 2011].

${ }^{2}$ Gamification applied within a non-virtual environment

${ }^{3}$ In this study, we understand framework as a systematic structure to guide the development of a project.
} 
Based on the exposed, we focus on addressing the following research question: "Which framework (6D or GAMIFY-SN) is more suitable for designing nonvirtual gamified classes?". To face this challenge, we present a quasi-experimental study to compare two gamification frameworks (GAMIFY-SN [Toda et al. 2019a] and 6D [Werbach and Hunter 2012]) for gamification design in the context of a gamified classroom. We chose these frameworks due to its previous application and validation in nonvirtual environments, and also their specificity (e.g., one is focused in the field of education and the other address a more general field). The comparison took place through the development of two gamified classes, each using one of the frameworks. The results indicate that one of the frameworks proved to be more adaptable to the context, however, the other was more complete in the sense of associating the elements of gamification with the instructor's final objectives in their class.

\section{Background}

This section aims to present the main related topic of our study, which is gamification design frameworks, with a special overview of the frameworks 6D and GAMIFY-SN. We also will present in this section our main related works.

\subsection{Gamification design frameworks}

In the last decade, studies have proposed frameworks for gamification design, recent research mapped more than 40 frameworks, where the majority are conceptual (which means that they have not been applied nor evaluated in a real scenario) [Mora et al. 2017]. These frameworks provide guidelines on how to design gamification in the best way, for their purposes (e.g., education, business, health, or tourism). However, less than ten of these frameworks are focused in the field of education, and most of them have not been used in real scenarios, or are focused exclusively in virtual environments [Mora et al. 2017, Toda et al. 2019a].

\subsubsection{D Framework}

The gamification design framework 6D was proposed by [Werbach and Hunter 2012]. They where the first to propose a systematic structure to support gamification design [Mora et al. 2017]. This framework is composed of six different steps: 1) Define Business Objectives; 2) Delineate target behaviour; 3) Describe your players; 4) Devise activity loops; 5) Don't forget the fun; and 6) Deploy appropriate tools [Werbach and Hunter 2012]. This framework starts from a definition of business objectives following by the definition of expected behaviours (e.g., to make students learn a content followed by sub-tasks as making students do an exercise list). Then, the designer needs to describe the players by providing demographic information or player types [Werbach and Hunter 2012, Mora et al. 2017]. Following, steps 4 and 5 consider the game elements provided by the framework to devise the activities always considering the fun part. Finally, the designer can deploy the gamification system with the appropriate tools [Werbach and Hunter 2012]. It is worth mentioning that the 6D framework was not created to be used in specific scenarios or domains it is considered a generic framework, with properties that can be adapted for different situations. 


\subsubsection{GAMIFY-SN Framework}

This framework was proposed by [Toda et al. 2019a], focused on the education domain (especially the education expert), and is composed of four steps: 1) Content definition; 2) Definition of the game elements; 3) Deployment; 4) Evaluation. These activities are divided between two roles (educator and designer), where one is concerned with the learning activities (educator) and the other with the game elements definition (designer) [Toda et al. 2019a]. The first step of the guideline requires the educator to organize and summarise their content in a knowledge structure (e.g., mind maps). Following, the designer can analyze the structure provided by the educator and propose gamified tasks, which are the union across the learning activity and the game elements. At the end of this step, both roles must agree on the mechanics and rules to begin the third step. In the deployment, the educator must explicit the rules to the classroom, observe, and take notes. The final step consists in evaluating the strategies, through the use of questionnaires [Toda et al. 2019a].

\subsection{Related works}

The use of frameworks for design gamified classrooms is not common. Usually, those frameworks are instantiated through virtual tools and applications. In this field, recent studies focused mainly on mapping existing frameworks [Mora et al. 2017, Toda et al. 2018b, Azouz and Lefdaoui 2018] but none of them specified its use in nonvirtual classes.

Concerned with gamified strategies in classrooms, [Gomes and Tedesco 2017] applied the $6 \mathrm{D}$ framework to design the gamification of a course, adapting this design to be used alongside Classcraft 4 . They've obtained the data from 134 students. Overall, through a qualitative analysis, the authors stated that the gamification increased the students' interest. However, the authors also states that different strategies should be considered to different levels of education, besides they've used an online gamification environment.

In a study conducted by [Silva et al. 2018], the authors used the 6D to design gamification strategies tied to instructional design. They used an ontology-based tool called SMARTIES alongside the 6D framework to create gamified content to a programming course. They've noted positive results towards students' perceived competence, motivation and interest during these courses. However, they reported that a small sample size $(n=12)$ would difficult the generalisation, and also they only applied the gamification strategies in four lessons (which was equivalent of $30 \%$ of the course).

In general, most of the studies that were found used frameworks to design gamification focused in virtual environments, or applied it partially in a course, focusing on multiple characteristics of the students. In this work, we present a new perspective on the educators' point of view alongside the comparison of using two different frameworks to design non-virtual lessons. Thus, as far as we know, we are the first to conduct a quasiexperimental study to compare two frameworks for the design of the non-digital gamified classes.

\footnotetext{
$\sqrt[4]{\text { https: / / www.classcraft.com/pt/ }}$
} 


\section{Study Design}

The study aimed to analyze two different frameworks in the design of an unplugged gamified class (without technology), in an attempt to answer the following questions: $i$ ) Is there a difference in the gamification design when using different frameworks? and ii) Which framework is more suitable (in terms of instruction perceptions) for designing non-virtual classes?

For this, a lecturer was invited to plan two different classes. As summarised in the Figure 1, in the first week, the lecturer planned the gamification design based on the GAMIFY-SN framework, and in the second week, the lecturer planned the gamification design using the 6D framework. During classes, the instructor conducted a real-time assessment (i.e., observed and noted in a logbook the actions that occurred in the class). After the class, they made a reflection and report on what the lecturer wrote during the classes. Both classes took place on weekends, with an interval of 15 days, divided as follows: three hours of class on Friday night and eight hours of class on Saturday (morning and afternoon). The classes were part of a course on Information Technology Management, Applied to Financial Institutions in the MBA of Corporate Finance, Auditing and Controlling, at a private Brazilian university.

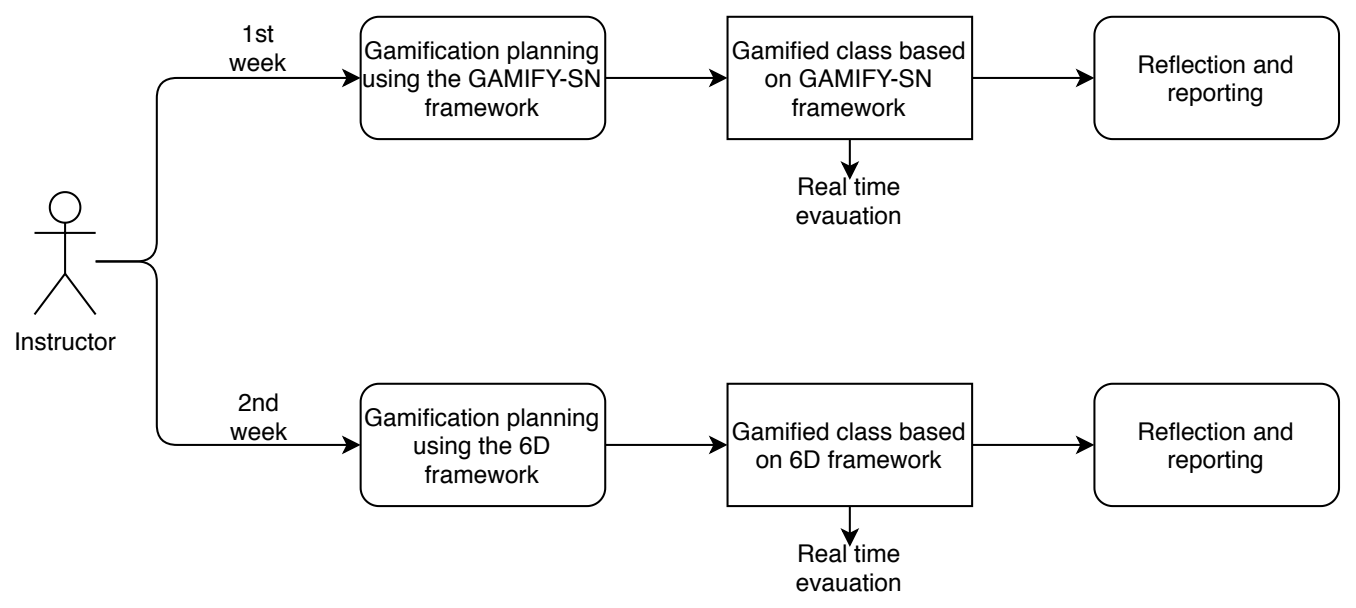

Figure 1. Study design

\subsection{Class design and participants}

The course in which the study took place aimed to present an overview of Information Technology (IT) applied to Financial Institutions, presenting a theoretical and practical view on IT Governance and Management, Information Security (Legislation and Standards applicable to IT Governance and Information Security) and Operational Risk (Errors, Fraud and Information Security Management Systems). The methodology of the course was characterised as theoretical/practical, with an oral presentation of subjects, discussion, and practical exercises, using resources such as slides, blackboard, and students' personal computers (to perform practical activities). The course was divided in two different classes.

The students enrolled in the course were 20 (14 female and six male). The students had different backgrounds (Business Administration, Law, and Finance), all aged 20 years old or over. Only one student had prior contact with the area of digital technologies. For 
group activities, five groups were created with four students. The division was made freely employing an agreement between the students themselves.

\subsection{Gamification designs}

In the first week, the lecturer planned the gamification design based on the GAMIFY-SN framework. The first step, was "definition of the content":

- Analysis of content: The analysis were based on the original lesson plan of the course, provided by the institution.

- Mapping of activities: Reading of manuals, development of tasks (proposal of solutions to real problems) and oral presentation.

- Mapping of social network features: Not considered in this class.

- Representation: $i$ ) presentation of the theoretical background, ii) presentation of a real case, iii) students division into groups, iii.i) reading of manuals, iii.ii) proposal of a solution, $i v$ ) presentation of the proposals.

The second step was the "definition of the game elements", where the lecturer organised the gamified tasks according to the six representations previously defined. The gamified tasks were group activities to create a document based on the COBIT framework ${ }^{5}$. The chosen gamification elements were: i) Points; ii) Progress; iii) Cooperation; iv) Competition; v) Narrative; vi) Pressure; vii) Secret [Toda et al. 2019b]. In this step, the lecturer acted as the designer, since they had previous experience with serious games.

The third step was the "deployment", activities were developed as recommended. Initially, the tasks and rules were presented, followed by the scavenging activities (no option was given for optional participation in the activities). Finally, the students' actions were observed and noted by the lecturer. The fourth step was not implemented during this course due to its length.

In the second week, the lecturer planned the gamification design based on the 6D framework. The first step was the "business objectives definition", where the lecturer made a list as concrete as possible and ranked them (i) improve the student's enjoyment; ii) improve the student's engagement (interaction with their colleagues). They eliminated the things which were not a final business objective (e.g., decrease the students' time to perform activities), and justified objectives (improve the class quality by having the students have a positive experience).

The second step was "delineate target behaviour", where the lecturer specified the tasks (e.g., in groups, create a document for managing financial institutions following the Balanced Scorecard framework 6 .

The third step was the "players description", where the lecturer defined that the players are 21 postgraduate students enrolled in the MBA in Corporate Finance, Auditing and Controlling. Because it is gamification in a traditional classroom, without using technologies, the lecturer opted to not make personalization at the level of types of player.

\footnotetext{
${ }^{5}$ Control Objectives for Information and Related Technologies, a best practices framework for information technology governance [De Haes and Van Grembergen 2015]

${ }^{6}$ semi-standard structured report, that can be used by managers to keep track of the execution of activities by the staff within their control and to monitor the consequences arising from these actions [Dumitrescu and Fuciu 2009]
} 
The fourth step was "devise activity loops", where the lecturer defined to use a students' enjoyment survey and observe the number of interactions during the class. The lecturer motivate students to participate in group activities, were the users implemented a document based on the BSC framework. The lecturer also provided immediate feedback giving tips to solve their doubts while conducting activities and providing small challenges to the students, organising the focus in small steps.

The fifth step was "fun strategies definition", that was provided through the competitions between the groups. Finally, the sixth step "appropriate tools definition" the lecturer chose not to use technological tools, using only the whiteboard to draw the game elements. The "success metrics definition", were the lecturer-defined win states for every tasks, student's enjoyment, and improve the student's interaction during the class.

\section{Results}

In the first week, the gamification design was planed using the GAMIFY SN framework [Toda et al. 2019a]. Regarding gamification planning, the instructor took about two hours from reading the material (framework itself) to composing the gamification design document. One of the main positive characteristics observed by the instructor was the completeness of the framework to allow associating the pedagogical objectives of the class with the gamification design.

The instructor highlighted the potential of the approach that was used, specifically in lesson planning without the use of digital technologies, allowing the instructor to use different non-digital instruments to propose the gamification design. On the other hand, the instructor highlighted as a negative aspect the difficulty of understanding the framework, which required a large amount of time and to identify what should be indicated in each section of the framework.

In the gamified class using the GAMIFY-SN framework, the instructor identified that it was possible to apply all the planned gamified elements (despite considering some elements too complex to be applied in the classroom context). Likewise, it was clear to the instructor that some elements were able to achieve their goals, such as the competition and cooperation elements, as the students cooperated in groups to make their respective groups obtain a higher score at the end of the class.

The planning for the second week was done using the 6D framework. Regarding the planning itself, the instructor managed to finish the whole process in about an hour. The main detail observed by the instructor was the freedom offered by the framework, which allowed the design to be shaped with greater creativity, without the need to explain many details related to the class, being able to keep the focus on the gamification planning, regardless of certain details related to the content of the class.

The instructor also highlighted the ease and speed in understanding the framework, and the fact that they could built the gamification design of the class quickly, just associating the elements to the class as a whole, and not needing to relate the gamification elements according to the structure of the class and activities proposed in class. On the other hand, the instructor emphasized that this freedom of the framework can make the elements of gamification become disconnected from the purpose of the class, leading students to focus only on gamification, in detriment of the educational activities. 
In the gamified class based on the 6D framework, the instructor noticed a greater interaction between students compared to the previous class. However, this may have occurred because the students were already familiarised with the methodology used in class. For this class, few elements of gamification were adopted, thus it became clearer the perception of the elements (competition and cooperation) during the class. At times, students were concerned about the grade they would receive for the activity, which may have occurred due to the non-direct relationship of the elements of gamification with educational activities.

In a direct comparison between the two frameworks, regarding the gamification design, according to the instructor's analysis, it was possible to notice that the 6D framework was considered easier to understand and more flexible concerning its documentation. On the other hand, GAMIFY-SN proved to be more related to educational activities, facilitating and encouraging the instructor to relate the elements of gamification to educational activities and to evaluate the proposed gamification in educational activities.

This likely occurred because the 6D framework was proposed for general situations, regardless of the type of activity to which it is being applied [Werbach and Hunter 2012], while GAMIFY-SN was proposed with the specific objective of being used in the design of gamified classes [Toda et al. 2018a]. Concerning the realization of the classes, it was possible to identify that in the planned lesson using the 6D framework, gamification was more separated from the pedagogical objectives of the class, which indicates that some mechanism may be necessary to lead the instructors to harness the potential of gamification in their educational goals.

Thus, in summary, in response to our research question and the question asked in the title of the article, we believe that the GAMIFY-SN framework was best for associating the elements of gamification with educational activities and, at the same time, associating each element with the instructor's educational objectives, while that the 6D framework was better in terms of adaptability, leaving the instructor free to make definitions regarding how to do the gamification design. Thus, we can understand that, specifically, for the gamification planning of non-digital gamified classes, the GAMIFY-SN framework presents better results.

\subsection{Limitations}

This study generated some limitations that must be considered in the interpretation of the results. Initially, the study was conducted in an MBA class with 20 students (in two classes, each using a different framework). Because the public and number of classes is small, our results might not generalize to other situations. Therefore, we suggest carrying out new studies that can replicate our assessment in other contexts. Similarly, only one instructor used the framework to carry out gamification design and made the observations, thus, the results also do not reflect the reality of other instructors.

Another limitation, concerned with the GAMIFY-SN framework, was that the instructor acted as both roles, which might have created some bias in the gamification design. To mitigate this situation, before stat the classes, the design was also validated with another designer, through a non-structured interview, asking which parts of it might be interesting to change. Finally, our study compared a framework created specifically for the planning of non-digital gamified classes (GAMIFY-SN) with a general-purpose frame- 
work (6 framework), this may also have generated threats concerning the study design, however, this decision was made due to the GAMIFY-SN framework, as far as we know, is the only one developed for this purpose and $6 \mathrm{D}$ is the most well-known general-purpose framework.

\subsection{Implications}

Within the given limitations, our results allowed us to gain some insights towards the current state-of-the-art and state-of-the-practice. Initially, the comparison between the two frameworks is a novelty, since no studies (up-to-now) compared the use of distinct frameworks to attest their efficiency in the design of gamification. This allowed us to understand the importance of having specific frameworks for different aspects (e.g., education) as they allow, among other things, to link the aspects inherent in gamification to business objectives (e.g., educational objectives of a class). Regarding the specific assessment of the GAMIFY-SN framework (focused on educational aspects), the study indicates that within the scenario in which it was applied, it fulfilled its objective of linking the aspects of gamification to the instructor's educational objectives. However, some limitations such as its complexity concerning readers' understanding of its stages can be revised and improved in future updates.

Based on the results, we can make some recommendations that can be followed by instructors and researchers interested in this field: $i$ ) associate the elements of gamification with educational activities: if there is no such association, students can maintain focus only on gamification and not dedicate to educational activities; ii) choose a framework based on your context: choosing a specific framework for your context can help you better associate the gamification design with the design of the proposed tasks; iii) use the framework in a flexibly way: following all steps of the frameworks can be difficult and make the activity complex, so try to understand which framework definitions are fundamental to your context and which can be made more flexible; $i v$ ) conduct constant evaluations: in addition to our results, due to the importance of maintaining a constant evaluation of the instruments used in the classroom, seek to make constant evaluations of your planned class via the framework with the traditional or gamified classes without following any framework, this will help to identify if the results are being relevant.

\section{Concluding Remarks}

Over the past 10 years, different frameworks for planning gamification have been proposed. However, there are still few studies showing the use of these frameworks by their end-users. Thus, in this study, we presented a comparison, from the perspective of the educator, on the use of two distinct frameworks for designing gamification. The study was conducted by building two gamification designs (one with each framework) to be applied in two gamified classes. Amongst our contributions, we can highlight: this is the first study to compare two frameworks in the design phase and to provide insights on the characteristics from a generic framework and an education-focused framework. As future work, we hope to compare these and other frameworks for gamification design through qualitative and quantitative studies, as well as conducting these assessments in different scenarios. We also aim to analyze the effects of applying these designs on students' motivation and performance, trough a quantitative study using experimental settings as control and focus groups. 


\section{Acknowledgements}

The authors would like to thank the funding provided by FAPESP (Projects: 2018/07688$1 ; 2016 / 02765-2 ; 2018 / 11180-3 ; 2018 / 15917-0)$, CAPES and CNPq.

\section{References}

Azouz, O. and Lefdaoui, Y. (2018). Gamification design frameworks: A systematic mapping study. In International Conference on Multimedia Computing and Systems -Proceedings, volume 2018-May, pages 1-9. IEEE.

De Haes, S. and Van Grembergen, W. (2015). Cobit as a framework for enterprise governance of it. In Enterprise governance of information technology, pages 103-128. Springer.

Deterding, S., Dixon, D., Khaled, R., and Nacke, L. (2011). From game design elements to gamefulness: defining gamification. In Proceedings of the 15th international academic MindTrek conference: Envisioning future media environments, pages 9-15. ACM.

Dumitrescu, L. and Fuciu, M. (2009). Balance scorecard-a new tool for strategic management. Buletin Stiintific, 14(2).

Gomes, T. and Tedesco, P. (2017). Gamificando a sala de aula: desafios e possibilidades em uma disciplina experimental de Pensamento Computacional no ensino fundamental. In Anais do Workshop de Informática na Escola, volume 23, page 1.

Gomes, T. J. G., dos Santos, W. O., Marques, L. B., da Silva Brito, P. H., and Bittencourt, I. I. (2019). Software requirements for the design of gamified applications for time management and tasks for children and adolescents with adhd. In Proceedings of the $X V$ Brazilian Symposium on Information Systems, pages 1-8.

Hamari, J., Shernoff, D. J., Rowe, E., Coller, B., Asbell-Clarke, J., and Edwards, T. (2016). Challenging games help students learn: An empirical study on engagement, flow and immersion in game-based learning. Computers in Human Behavior, 54:170179.

Monterrat, B., Lavoué, E., and George, S. (2014). Motivation for learning: Adaptive gamification for web-based learning environments. In 6th International Conference on Computer Supported Education (CSEDU 2014), pages 117-125.

Mora, A., Riera, D., González, C., and Arnedo-Moreno, J. (2017). Gamification: a systematic review of design frameworks. Journal of Computing in Higher Education.

Morschheuser, B., Hamari, J., Werder, K., and Abe, J. (2017). How to gamify? a method for designing gamification. In Proceedings of the 50th Hawaii International Conference on System Sciences 2017. University of Hawai'i at Manoa.

Oliveira, W. and Bittencourt, I. I. (2019). Tailored Gamification to Educational Technologies. Springer.

Oliveira, W., Toda, A., Toledo, P., Shi, L., Vassileva, J., Bittencourt, I. I., and Isotani, S. (2020). Does tailoring gamified educational systems matter? the impact on students' flow experience. In Proceedings of the 53rd Hawaii International Conference on System Sciences, pages 1226-1235. 
Pastushenko, O., Oliveira, W., Isotani, S., and Hruška, T. (2020). A methodology for multimodal learning analytics and flow experience identification within gamified assignments. In Extended Abstracts of the 2020 CHI Conference on Human Factors in Computing Systems, pages 1-9.

Rapp, A., Hopfgartner, F., Hamari, J., Linehan, C., and Cena, F. (2019). Strengthening gamification studies: Current trends and future opportunities of gamification research.

Rauschenberger, M., Willems, A., Ternieden, M., and Thomaschewski, J. (2019). Towards the use of gamification frameworks in learning environments. Journal of Interactive Learning Research, 30(2):147-165.

Santos, W. O., Toda, A., Isotani, S., and Bittencourt, I. I. (2018). Does gamified educational systems change students' learning behaviors? a case study with postgraduate students. RENOTE-Revista Novas Tecnologias na Educação, 16(2):11-20.

Silva, F., Toda, A., and Isotani, S. (2018). Towards a link between Instructional Approaches and Gamification - A Case Study in a Programming Course. Anais do Workshop de Informática na Escola, 24(1):157.

Toda, A. M., do Carmo, R. M., da Silva, A. P., Bittencourt, I. I., and Isotani, S. (2019a). An approach for planning and deploying gamification concepts with social networks within educational contexts. International Journal of Information Management, 46:294-303.

Toda, A. M., do Carmo, R. M., da Silva, A. P., and Isotani, S. (2018a). Gamify-sn: A meta-model for planning and deploying gamification concepts within social networksa case study. In World Conference on Information Systems and Technologies, pages 1357-1366. Springer.

Toda, A. M., dos Santos, W. O., Klock, A. C., Gasparini, I., Bittencourt, I. I., and Isotani, S. (2018b). Frameworks para o planejamento da gamificaçao em contextos educacionais-uma revisao da literatura nacional. RENOTE-Revista Novas Tecnologias na Educação, 16(2):505-514.

Toda, A. M., Klock, A. C., Oliveira, W., Palomino, P. T., Rodrigues, L., Shi, L., Bittencourt, I., Gasparini, I., Isotani, S., and Cristea, A. I. (2019b). Analysing gamification elements in educational environments using an existing gamification taxonomy. Smart Learning Environments, 6(1):16.

Toda, A. M., Valle, P. H., and Isotani, S. (2017). The dark side of gamification: An overview of negative effects of gamification in education. In Researcher Links Workshop: Higher Education for All, pages 143-156. Springer.

Werbach, K. and Hunter, D. (2012). For the win: How game thinking can revolutionize your business. Wharton Digital Press. 